\title{
Multiparametric Optimization of Low Plasticity Burnishing Process for AISI 4340 by using Utility Concept
}

\author{
A.P. Kalmegh, P.M. Khodke
}

\begin{abstract}
Low plasticity burnishing (LPB囚) is an innovative method which provides deep and stable compressive residual stresses. It improves surface characteristic such as low and high cycle fatigue strength, surface finish, microhardness, wear resistance, corrosion resistance, etc. The objective of the multi parametric process optimization for $L P B$ is to find out appropriate levels of process variables i.e. ball diameter, pressure, speed, initial surface roughness and number of passes for achieving optimum values of surface roughness, hardness and fatigue life simultaneously. Considering multiple output responses in the present study, multi response optimization is essential. This paper deals with multi objective LPB process optimization problem of response characteristics with Utility concept for AISI 4340 steel alloy.

$\angle P B \AA$ is a registered trademark of Lambda Technologies group.
\end{abstract}

Index Terms: LPB, surface roughness $(R a)$, surface hardness (Hw), fatigue life (FL), AISI 4340, Utility Concept

\section{INTRODUCTION}

For surface enhancements there are many methods. Some of the methods are shot peening, laser peening, water peening, liquid peening, conventional peening, burnishing etc [1]. Out of these methods burnishing is economical tool with simple construction as compared to super finishing, polishing, grinding etc. But as compared to the above methods low plasticity burnishing (LPB®) is an innovative method which produces less cold work with higher depth of compressive residual stresses. The LPB improves surface finish, micro hardness of the surface, corrosion resistance, out of roundness and straightness, wear resistance low and high cycle fatigue strength, foreign object damage (FOD) tolerance, etc. Deep stable layer of compressive residual stress can introduce with LPB, with low cost as compared to the other surface enhancement methods. LPB process can perform on CNC and well as conventional machine tool.

Most of the research work on LPB is done by Paul S. Prevey.Preveyshowed the effect of residual stress and

Revised Manuscript Received on July 09, 2019

\section{A.P. Kalmegh,}

Dr. P.M. Khodke

Research Scholar, Department of Mechanical Engineering, Government Engineering College, Amravati, India

Principal, Department of Mechanical Engineering, Government Engineering College, Karad, India percentage of cold work on depth of compressive layers and residual stresses for material IN718, Ti-6-4 and 17-4 PH steel [2].LPB is also found to improve high cycle fatigue dimension and tolerance of Ti6-Al-4V turbine engine compressor [3]. P.R. Prabhu et.al [4] used LPB for improvement in surface finish for AISI 4140.

Prevey, et.al [5] compared the residual stress and cold work distribution of IN718material produced by LPB with other surface treatment.It has also been studied minimum cold work offers greatest resistance to thermal relaxation at elevated temperature.It is also claimed that 100 times more fatigue life can be obtained for AA 7075-T6 using LPB which is caused due to reduction in corrosion mechanism for AA 7075-T6 [6].

The first LPB model available in literature is developed by Seemikeri [7] with experimental data for enhancement of surface finish, hardness and fatigue life for AISI 1045 considering ball diameter, speed, pressure and number of tool passes as input parameter.Dusaet.al [8] presented mathematical model based on Hook's law and validated using Taguchi orthogonal array considering speed, part diameter and number of passes. Gulhane, et.al [9] also developed experimental model for 316L SS, Ti-6Al-4V, for enhancement of surface finish. Prevey claimed that micro cracks of Ti6-Al-4V can be freely arrested by LPB to the depth of $0.75 \mathrm{~mm} \mathrm{[10].}$

An attempt on optimization of LPB by considering all response parameters simultaneously is expected to provide more clarity about usefulness of the process. This paper presents optimization of LPB process with Utility concept to achieve the superior surface finish, increased hardness with high fatigue life for a low cost material AISI 4340 steel alloy.

\section{MULTI OBJECTIVE PROCESS OPTIMIZATION}

The objective of the multi parametric process optimization for LPB is to find out appropriate levels of process variables i.e. ball diameter, pressure, speed, initial surface roughness and number of passes for achieving optimum values of surface roughness, hardness and fatigue life simultaneously. Considering multiple output responses in the present study, multi response optimization is essential.

This paper deals with multi objective LPB process optimization problem of response characteristics with Utility concept for AISI 
4340 steel alloy on standard specimen $[11,12]$.

\section{Utility Concept}

Utility can be defined as the usefulness of a product or a process with reference to the levels of expectations to the consumers. The utility theory assumes that any decision is made on the basis of the utility maximization principle, according to which, the best choice is the one that provides the highest satisfaction to the decision maker. The weight for each criterion (response) is obtained by intuition and judgment of the decision maker. The performance evaluation of any system depends on number of output characteristics. Therefore, a combined measure is necessary to gauge its overall performance, which must take into account the relative contribution of all quality characteristics. Hence Utility concept requires the priority weight of each response to calculate the overall utility index. Such a composite index represents the overall utility of a product/process. Utility concept has been explored in this work to aggregate multiple responses (objective functions) into an equivalent quality index (single objective function). The overall utility index is then optimized (maximized) finally [13].

The overall usefulness of a process/product can be represented by a unified index termed as Utility which is the sum of the individual utilities of various quality characteristics of the process/product. The methodological basis for Utility approach is to transform the estimated response of each quality characteristic into a common index. If $\mathrm{X}_{\mathrm{i}}$ is the measure of effectiveness of an attribute (or quality characteristic) $i$ and there are $n$ attributes evaluating the outcome space, then the Joint Utility Function can be expressed as:

$$
\begin{aligned}
& U\left(X_{1}, X_{2}, \ldots X_{n}\right)= \\
& f\left(U_{1}\left(X_{1}\right), U_{2}\left(X_{2}\right), \ldots \ldots \ldots U_{n}\left(X_{n}\right)\right)
\end{aligned}
$$

Where $U_{i}\left(X_{i}\right)$ is the utility of the $i^{\text {th }}$ attribute

The overall Utility function is the sum of individual utilities if the attributes are independent, and is given as follows:

$$
U\left(X_{1}, X_{2}, \ldots X_{n}\right)=\sum_{i=1}^{n} U_{i}\left(X_{i}\right)
$$

The attributes may be assigned weights depending upon the relative importance or priorities of the characteristics. The overall utility function after assigning weights to the attributes can be expressed as:

$$
U\left(X_{1}, X_{2}, \ldots X_{n}\right)=\sum_{i=1}^{n} W_{i} U_{i}\left(X_{i}\right)
$$

Where $\mathrm{W}_{\mathrm{i}}$ is the weight assigned to the attribute $\mathrm{i}$, the sum of the weights for all the attributes must be equal to 1 .

\section{Determination of Utility Value}

A preference scale for each quality characteristic is constructed for determining its utility value. Two arbitrary numerical values (preference number) 0 and 9 are assigned to the just acceptable and the best value of the quality characteristic respectively. The preference number $\left(\mathrm{P}_{\mathrm{i}}\right)$ can be expressed on a logarithmic scale as follows:

$$
P i=A \times \log \left[\frac{x_{i}}{X_{i}^{l}}\right]
$$

Where $X_{i}=$ value of any quality characteristic or attribute $i$ $X_{i}^{I}=$ just acceptable value of quality characteristic or attribute $\mathrm{i}$

$\mathrm{A}=$ constant and can be found by the condition that

At optimum value $\left(X_{i}^{*}\right)$ of attribute $i, P_{i}=9$

$$
\text { Therefore, } A=\frac{9}{\log \frac{X^{*}}{X_{i}}}
$$

The overall utility can be expressed as;

$$
U=\sum_{i=1}^{n} W_{i} P_{i}
$$

Subject to condition that $\sum_{i=1}^{n} W_{i}=1$

\section{Experimental Plan}

Experimentation is carried out on standard fatigue component for AISI 4340 steel alloy [11, 12]. In the present study the objective is to optimize the process for three responses simultaneously. Initially the single factor experimentation is conducted to identify significant factors [11]. The five variables along with their operating ranges have been identified to have significant effect on three output responses. Experimental design methodology, modeling and analysis are carried out to compress the range of input

\begin{tabular}{|c|c|c|c|c|c|c|c|c|}
\hline Ex. No. & $\begin{array}{l}\text { BD } \\
(\mathrm{mm})\end{array}$ & $\begin{array}{l}\mathrm{N} \\
\text { (rpm) }\end{array}$ & $\begin{array}{l}\mathbf{P} \\
\left(\mathrm{Kg} / \mathrm{cm}^{2}\right)\end{array}$ & NP & $\begin{array}{l}\text { Rai } \\
(\mu \mathrm{m})\end{array}$ & $\begin{array}{l}\text { Ra } \\
(\mu \mathrm{m})\end{array}$ & $\begin{array}{l}\mathbf{H}_{\mathrm{w}} \\
(\mathbf{H v})\end{array}$ & FL $* 10^{5}$ \\
\hline 1 & 6 & 180 & 19 & 2 & 5 & 1.042 & 463 & 1.110 \\
\hline
\end{tabular}
parameters to reach optimal at the earliest [12].

The experiments were carried out with half factorial design with two levels, two replicates and five input factors (25-1). The experimental observations for the plan for each of the 3 response parameters are given in Table 1.

Table 1 Experimental data for $2^{5-1}$ Plan 


\begin{tabular}{|c|c|c|c|c|c|c|c|c|}
\hline 2 & 6 & 180 & 19 & 1 & 3 & 0.669 & 419 & 1.325 \\
\hline 3 & 6 & 224 & 22 & 2 & 5 & 0.458 & 529 & 1.180 \\
\hline 4 & 5 & 224 & 22 & 2 & 3 & 0.189 & 524 & 1.754 \\
\hline 5 & 5 & 180 & 19 & 1 & 5 & 1.289 & 431 & 1.300 \\
\hline 6 & 5 & 180 & 22 & 2 & 5 & 0.813 & 539 & 1.390 \\
\hline 7 & 5 & 224 & 22 & 1 & 5 & 0.618 & 449 & 1.590 \\
\hline 8 & 6 & 180 & 22 & 1 & 5 & 1.418 & 455 & 1.150 \\
\hline 9 & 5 & 180 & 19 & 2 & 3 & 0.389 & 445 & 1.483 \\
\hline 10 & 5 & 180 & 22 & 1 & 3 & 0.538 & 452 & 1.423 \\
\hline 11 & 5 & 224 & 19 & 2 & 5 & 0.836 & 461 & 1.440 \\
\hline 12 & 5 & 224 & 19 & 2 & 5 & 0.751 & 441 & 1.640 \\
\hline 13 & 5 & 224 & 19 & 1 & 3 & 0.573 & 421 & 1.770 \\
\hline 14 & 5 & 224 & 22 & 1 & 5 & 0.519 & 462 & 1.480 \\
\hline 15 & 6 & 180 & 19 & 2 & 5 & 0.989 & 461 & 1.190 \\
\hline 16 & 6 & 224 & 19 & 2 & 3 & 0.489 & 431 & 1.461 \\
\hline 17 & 6 & 224 & 22 & 1 & 3 & 0.293 & 405 & 1.453 \\
\hline 18 & 6 & 224 & 22 & 2 & 5 & 0.438 & 535 & 1.350 \\
\hline 19 & 5 & 180 & 22 & 1 & 3 & 0.518 & 461 & 1.523 \\
\hline 20 & 5 & 180 & 19 & 2 & 3 & 0.398 & 454 & 1.593 \\
\hline 21 & 5 & 224 & 22 & 2 & 3 & 0.109 & 517 & 1.730 \\
\hline 22 & 5 & 180 & 19 & 1 & 5 & 1.313 & 451 & 1.190 \\
\hline 23 & 6 & 224 & 19 & 1 & 5 & 1.456 & 415 & 1.181 \\
\hline 24 & 6 & 180 & 22 & 1 & 5 & 1.396 & 461 & 1.143 \\
\hline 25 & 6 & 224 & 19 & 2 & 3 & 0.468 & 441 & 1.431 \\
\hline 26 & 5 & 180 & 22 & 2 & 5 & 0.819 & 555 & 1.310 \\
\hline 27 & 6 & 180 & 19 & 1 & 3 & 0.658 & 415 & 1.309 \\
\hline 28 & 6 & 180 & 22 & 2 & 3 & 0.429 & 510 & 1.408 \\
\hline 29 & 6 & 224 & 19 & 1 & 5 & 1.318 & 411 & 1.140 \\
\hline 30 & 6 & 224 & 22 & 1 & 3 & 0.271 & 441 & 1.399 \\
\hline 31 & 5 & 224 & 19 & 1 & 3 & 0.531 & 425 & 1.509 \\
\hline 32 & 6 & 180 & 22 & 2 & 3 & 0.412 & 541 & 1.423 \\
\hline
\end{tabular}

\section{Preference Scale Construction}

The preference scale is constructed on the basis of equations 4 and 5. For an example, preference scale is constructed for surface roughness is as follow,

To optimize for Ra, the value is selected as smaller is better. With reference to Table 1;

$\mathrm{X}^{*}=$ maximum acceptable value for $\mathrm{Ra}=1.456 \mu \mathrm{m}$

$\mathrm{X} 1$ = optimal value of $\mathrm{Ra}=0.109 \mu \mathrm{m}$

Using these values and equation (4) and (5), the preference scale $(\mathrm{Ra})$ surface roughness is constructed as,

$$
P_{R a}=7.994 \times \log \left[\frac{X_{R a}}{0.109}\right]
$$

Another example to construct preference scale for $\mathrm{H}_{\mathrm{w}}$ with criteria Higher is better is explained below,

To optimize, the value of $\mathrm{H}_{\mathrm{w}}$ is selected as Higher is better, Hence,

$\mathrm{X}^{*}=$ optimal value for $\mathrm{H}_{\mathrm{w}}=555 \mathrm{Hv}$ (refer to Table 1)

$\mathrm{X} 1$ = minimum acceptable value $\mathrm{H}_{\mathrm{w}}=405 \mathrm{Hv}$

\section{Published By:}

IJITEE 
Using these values and equation (5), the preference scale $\mathrm{H}_{\mathrm{w}}$ is constructed as

$P_{H w}=65.771 \times \log \left[\frac{X_{H w}}{405}\right]$

$$
P_{F L}=44.421 \times \log \left[\frac{X_{F L}}{1110318}\right]
$$

Table 2 provides calculated value of constant A for all responses.

Similarly, for all remaining response of FL higher is better condition is applicable

Table 2 Calculations of Intermediate Constants

\begin{tabular}{|l|l|l|l|l|l|}
\hline \multicolumn{2}{|l|}{ Lower is better } & \multicolumn{2}{l|}{ Higher is better } & \multicolumn{2}{l|}{ Higher is better } \\
\hline $\mathrm{Ra}$ & $\mathrm{H} \mathrm{H}_{\mathrm{w}}$ & $\mathrm{Fl}$ & \\
\hline $\mathrm{X}$ & $\mathrm{X} 1$ & $\mathrm{X}^{*}$ & $\mathrm{X} 1$ & $\mathrm{X}$ & $\mathrm{X} 1$ \\
\hline 1.456 & 0.109 & 555 & 405 & 1770329 & 1110318 \\
\hline $\mathrm{A}=7.994778$ & $\mathrm{~A}=65.77122$ & \multicolumn{2}{l|}{$\mathrm{A}=44.42106$} \\
\hline
\end{tabular}

The decision maker has to assign weights. Normally, every parameter is assigned equal weights, here three output parameters are analyzed, and hence weight of $1 / 3$ is equally assigned to each response.

$W_{R a}=W_{H w}=W_{F L}=1 / 3$

\section{Utility Value Calculation}

The utility value of each experiment is calculated using equation (10).

$$
\begin{aligned}
& U(n, R)=P_{R a} \times W_{R a}+P_{H w} \times W_{H w}+P_{F L} \times \\
& W_{F L}
\end{aligned}
$$

Where, $n=$ trial number, $1,2 \ldots \ldots .32$;

$R=$ replication number,

$R=1,2$

The utility values are calculated using MINITAB analysis software and reported in Table 3

Table 3 Utility Data Based on Response Characteristics (1/3 weightage)

\begin{tabular}{|l|l|l|l|l|l|l|}
\hline $\mathrm{Ra}$ & $\mathrm{U} \mathrm{Ra}$ & $\mathrm{H}_{\mathrm{w}}$ & $\mathrm{U} \mathrm{H}_{\mathrm{w}}$ & $\mathrm{FL}$ & $\mathrm{U} \mathrm{FL}$ & $\mathrm{U}$ overall \\
\hline 1.042 & 8.16785 & 463 & 1770.056 & 1110318 & 0 & 592.7414 \\
\hline 0.669 & 4.21474 & 419 & 406.7306 & 1325395 & 4527401 & 1509271 \\
\hline 0.458 & 2.28285 & 529 & 4036.008 & 1180111 & 1387892 & 463976.7 \\
\hline 0.189 & 0.3612 & 524 & 3855.717 & 1754553 & 15487989 & 5163949 \\
\hline 1.289 & 11.0561 & 431 & 766.0103 & 1300311 & 3962410 & 1321062 \\
\hline 0.813 & 5.67226 & 539 & 4400.627 & 1390518 & 6036567 & 2013658 \\
\hline 0.618 & 3.72328 & 449 & 1322.745 & 1590331 & 11023329 & 3674885 \\
\hline 1.418 & 12.6321 & 455 & 1512.945 & 1150238 & 783811 & 261778.9 \\
\hline 0.389 & 1.71838 & 445 & 1197.215 & 1483138 & 8283690 & 2761630 \\
\hline 0.538 & 2.98234 & 452 & 1417.561 & 1423029 & 6812177 & 2271199 \\
\hline 0.836 & 5.91371 & 461 & 1705.406 & 1440113 & 7225512 & 2409074 \\
\hline 0.751 & 5.03284 & 441 & 1072.712 & 1640512 & 12354356 & 4118478 \\
\hline 0.573 & 3.30175 & 421 & 465.9363 & 1770329 & 15932961 & 5311143 \\
\hline 0.519 & 2.81222 & 462 & 1737.7 & 1480193 & 8210484 & 2737408 \\
\hline 0.989 & 7.57314 & 461 & 1705.406 & 1190363 & 1598585 & 533432.7 \\
\hline 0.489 & 2.54857 & 431 & 766.0103 & 1461330 & 7744279 & 2581683 \\
\hline 0.293 & 1.00598 & 405 & 0 & 1453331 & 7547997 & 2515999 \\
\hline 0.438 & 2.11526 & 535 & 4254.137 & 1350332 & 5098161 & 1700806 \\
\hline
\end{tabular}




\begin{tabular}{|l|l|l|l|l|l|l|}
0.518 & 2.80333 & 461 & 1705.406 & 1523952 & 9309758 & 3103822 \\
\hline 0.398 & 1.78974 & 454 & 1481.087 & 1593229 & 11099375 & 3700286 \\
\hline 0.109 & 0 & 517 & 3605.602 & 1730249 & 14807845 & 4937150 \\
\hline 1.313 & 11.346 & 451 & 1385.892 & 1190193 & 1595077 & 532158.2 \\
\hline 1.456 & 13.1044 & 415 & 289.1385 & 1181543 & 1417218 & 472506.9 \\
\hline 1.396 & 12.3604 & 461 & 1705.406 & 1143113 & 641928.2 & 214548.6 \\
\hline 0.468 & 2.36779 & 441 & 1072.712 & 1431229 & 7010079 & 2337051 \\
\hline 0.819 & 5.73503 & 555 & 4995 & 1310003 & 4179615 & 1394872 \\
\hline 0.658 & 4.10756 & 415 & 289.1385 & 1309119 & 4159747 & 1386680 \\
\hline 0.429 & 2.04087 & 510 & 3358.195 & 1408663 & 6467663 & 2157008 \\
\hline 1.318 & 11.4066 & 411 & 172.6478 & 1140339 & 586919.9 & 195701.3 \\
\hline 0.271 & 0.857 & 441 & 1072.712 & 1399209 & 6242485 & 2081186 \\
\hline 0.531 & 2.91939 & 425 & 585.1607 & 1509563 & 8945581 & 2982056 \\
\hline 0.412 & 1.90215 & 541 & 4474.189 & 1423112 & 6814176 & 2272884 \\
\hline
\end{tabular}

\section{Determination of Optimal Setting of Parameters}

Utility values are analyzed for mean response. Since overall utility is 'higher is better' is selected, the corresponding mean ratios for utility values as single response and the condition "higher is better" are estimated and depicted in Table 4.Considering 'larger the better criteria', values of different variables for combined optimum response, based on mean, are shown. It shows that lower level for BD and Rai and higher level for N, P and NP should be preferred to get optimum performance. The rank indicates the significance level of effect of a variable on response, with $33 \%$ weightage.

Table 4 Response Table for Mean of Utility Values with Ranking ( $1 / 3$ weightage)

\begin{tabular}{|l|l|l|l|l|l|}
\hline LEVEL & BD & N & P & NP & Rai \\
\hline L-1 & $\mathbf{3 0 2 7 0 5 2}$ & 1589680 & 2009550 & 1910713 & $\mathbf{2 9 4 2 0 6 2}$ \\
\hline L-2 & 1292819 & $\mathbf{2 7 3 0 1 9 1}$ & $\mathbf{2 3 1 0 3 2 1}$ & $\mathbf{2 4 0 9 1 5 8}$ & 1377809 \\
\hline Delta & 1734233 & 1140511 & 300771 & 498445 & 1564253 \\
\hline RANK & 1 & 3 & 5 & 4 & 2 \\
\hline
\end{tabular}

\section{Conclusion}

It is further observed that the optimum level of input variables, the utility values and also the optimum values of all three response parameters ( $\mathrm{Ra}, \mathrm{Hw}$ and $\mathrm{FL}$ ) remained unchanged even after the weightages for response function were varied, except when the weightages of any one of the output parameter is considered $100 \%$ neglecting others.

1. For optimization, the maximum utility value is obtained to minimize the surface roughness and to maximize surface hardness and fatigue life.
2. The ranking of the input variables as per Utility value is in the order of Ball Diameter (BD), Initial Surface Roughness (Rai), Speed (N), Number of Passes (NP) and Pressure (P).

3. The multi-parametric optimization with equal weightages (1/3rd) and utility concept yielded the following levels of variables for the test conditions chosen for 25-1 fractional factorial plan.

$$
\begin{aligned}
& \mathrm{BD}=5 \mathrm{~mm}, \\
& \mathrm{~N}=224 \mathrm{rpm}, \\
& \mathrm{P}=22 \mathrm{Kg} / \mathrm{cm} 2, \\
& \mathrm{NP}=2 \text { and } \\
& \text { Rai }=3 \mu \mathrm{m}
\end{aligned}
$$

4. The various combinations of weightages for the response functions used in the work have been tried with method of Utility concept and observed that the change in weightage does not result in change in the level of input variables and also the values of different response functions except when the weightage for any one of the output parameter is considered $100 \%$, neglecting others.

\section{REFERENCES}

[1] M.M. EL-Khabeery ,M.H.EL-Axir, 'Experimental techniques for studying the effects of milling roller-burnishing parameters on surface integrity', International Journal of machine tools and manufacture 41,2001, 1705-1719.

[2] Paul S.Prevey, Ravi A.Ravindranath, "Case studies of fatigue life improvement using low plasticity burnishing in gas turbine engine application', Journal of engineering for gas turbines \& power, Vol.128/865 October 2006

[3] Paul S.Prevey , N.Jayaraman ,Ravi A.Ravindranath, Michael Shepard, 'Improved high cycle fatigue damage tolerance of turbine- engine compressor components by low plasticity burnishing', Journal of engineering for gas turbines \& power, Vol.130/012102-1, January 2008.

[4] P.R.Prabhu, S.M.Kulkarni, S.S.Sharma, 'Influence of deep cold rolling and low plasticity burnishing on surface hardness and surface roughness of AISI 4140 Steel', World

Academy of Science, Engineering and Technology 72 , 2010 . 
[5] Paul S.Prevey, Lambda Research, Cincinnati, OH, 'The effect of cold work on the thermal stability of residual compression in surface Enhanced IN718', 20th ASM Materials Solution Conferences \& Exposition St.Louis Missouri, october 10-12,2000.

[6] Paul S.Prevey, John T. Cammett, 'The Influence of surface enhancement by low plasticity burnishing on the corrosion fatigue performance of AA7075-T6', International Journal of Fatigue 26, 2004, page975-982.

[7] C.Y.Seemikeri ,P.K.Brahmankar, S.B.Mahagaonkar, 'Investigation on surface integrity of AISI 1045 using LPB tool', Tribology International 41, 2008, page 724-734.

[8] PetruDusa\& Gabriel Dumitriu, 'Analytical method of residual stress evolution into superficial layers at low plasticity burnishing (LPB)', international Journal of Materials Processing Technology ISSN 2067-3604, Vol.1,No.1/2009.

[9] U.D.Gulhane, S.B.Mishra, P.K.Mishra, 'Enhancement of surface roughness of 316L stainless steel and TI-6AL-4V using low plasticity burnishing: DOE approach', Intyernational journal Mechanical Engineering \& Technology, Vol.3, Issue 1, January-April2012, PP.150-160.

[10] Paul S.Prevey, N.Jayaraman, Ravi A.Ravindranath, Michael Shepard, 'Mitigation of fretting fatigue damage in blade and desk pressure faces with low plasticity burnishing (LPB)',

[11] A. P. Kalmegh, Dr. P. M. Khodke, 'Single factor experimentation on low plasticity burnishing process for AISI 4340', International journal of advance research in science and engineering, Vol.No. 07, Special issue No. (02), February 2018

[12] A. P. Kalmegh, Dr. P. M. Khodke, "Design of Experimentation for Composite Desirability of Low Plasticity Burnishing Process for AISI 4340, International Journal of Pure and Applied Mathematics, Volume 120, No. 6 (2018)

[13] RinaChakravorty, Susanta Kumar Gauri and Shankar Chakraborty, 'Optimization of Multiple Responses of Ultrasonic Machining (USM) Process: A Comparative Study' International Journal of Industrial Engineering Computations, 4 (2013),285-296 